\title{
Improved stress prediction in adhesive bonded optical components
}

\author{
J. de Vreugd ${ }^{\text {1a }}$, M.J.A. te Voert $^{\mathrm{a}}$, J.R. Nijenhuis ${ }^{\mathrm{a}}$, J.A.C.M. Pijnenburg ${ }^{\mathrm{a}}$, E. Tabak ${ }^{\mathrm{a}}$ \\ ${ }^{a}$ TNO optomechatronics, Stieltjesweg 1, 2628 CK, Delft, the Netherlands.
}

\begin{abstract}
Adhesives are widely used in optomechanical structures for bonding optical components to their mounts. The main advantage of using adhesives is the excellent strength to weight ratio. Adhesive bonding is seen as a desirable joining technique as it allows for greater flexibility in design. A disadvantage of adhesives however is the limited dimensional stability and loadability. To design stable optical mounts, accurate prediction of stresses and deformation is therefore needed.

Adhesives show strong temperature and loading history dependent behavior. Viscoelastic material models are needed for accurate prediction of stresses and strains in bonded joints. However, representative material data for adhesives is difficult to find.

In this research, an experimental framework is build up to determine relevant mechanical properties of adhesives for improving stress and deformation prediction. This paper shows the results of the characterization experiments and modeling techniques. Also the implementation of material models in finite element code is briefly discussed. The obtained models are used in the mount design in the EUCLID and TROPOMI programs as described in "Ultra stable isostatic bonded optical mount design for harsh environments, J.A.C.M Pijnenburg et al” (this conference).
\end{abstract}

Keywords: optical mounts, optomechanics, thermo mechanical stress, adhesive properties, viscoelasticity

\section{INTRODUCTION}

Mounting optical components for use in space missions is challenging. Both the bonding connection and the optical components have to withstand high acceleration loads during launch and extreme temperatures while operating in space. Furthermore, the stability of optical mounts should not be affected by external loadings. Prediction of mount stability and possible bond failure is therefore needed. For accurate prediction of stresses in bonded joints, representative material data is needed. Available material data is often limited to properties as Young's modulus and the coefficient of thermal expansion (CTE) at room temperature while neglecting non-linear behavior under changing temperature and aging conditions [1].

Adhesives are polymers which show strong temperature dependent behavior. Polymers are rigid glasses below a certain, material specific temperature known as the glass transition temperature $\left(T_{g}\right)$. At temperatures above $T_{g}$ the polymer behaves soft and flexible and is either an elastomer in case of thermoset material or a viscous fluid in case of a thermoplastic material. Also other physical properties as heat capacity, thermal expansion coefficient, mechanical damping, electrical properties and tensile strength change dramatically at $T_{g}$. Since material properties show profound changes in the region of $T_{g}$, the glass transition temperature is of large technological importance. The glass transition temperature thus determines the lower use temperature limit of a rubber and the upper limit of a thermoplastic or thermoset material.

In order to improve the existing adhesive material models, viscoelastic characterization experiments were performed on 5 different adhesives types. The materials are here named as adhesive A - E:

*jan.devreugd@ @tno.nl phone+31(0)8886 62430

Modern Technologies in Space- and Ground-based Telescopes and Instrumentation II,
edited by Ramón Navarro, Colin R. Cunningham, Eric Prieto, Proc. of SPIE Vol. 8450, 84504A

Updated 1 March 2012

(c) 2012 SPIE · CCC code: 0277-786X/12/\$18 - doi: 10.1117/12.925418

Proc. of SPIE Vol. $845084504 \mathrm{~A}-1$ 


\begin{tabular}{|l|l|}
\hline Material: & Details \\
\hline A & UV curing adhesive \\
\hline B & Epoxy \\
\hline C & Electrically conductive silicone rubber \\
\hline D & Silicon rubber \\
\hline E & Elastomeric epoxy \\
\hline
\end{tabular}

This paper describes the measurements done to obtain the following mechanical properties as a function of temperature:

- CTE

- Viscoelastic shear modulus

- Viscoelastic Young's modulus

- Elastic temperature dependent bulk modulus

\section{CTE MEASUREMENTS}

The coefficient of thermal expansion is measured in a broad temperature range: $-150{ }^{\circ} \mathrm{C}-+100{ }^{\circ} \mathrm{C}$. For this purpose, adhesive bars are manufactured with dimensions: [ $30 \mathrm{X} 5 \mathrm{X} 0.5 \mathrm{~mm}$ ]. A miniature tensile tester of TA instruments is used for CTE measurements. This tensile tester is equipped with a programmable furnace. By heating the samples with a heating rate of $1{ }^{\circ} \mathrm{C} / \mathrm{min}$ and measuring length changes, the coefficient of thermal expansion could be calculated. The measured thermal strains of material A ,B C, D, E are given in Figure 1.

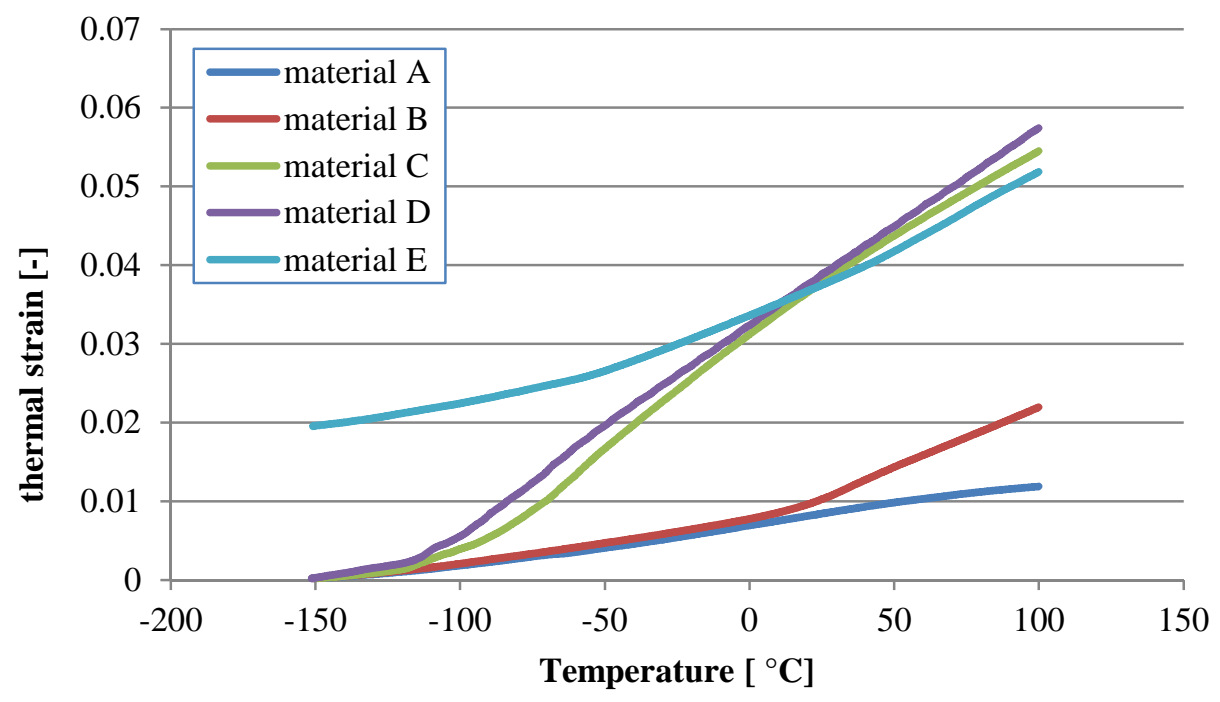

Figure 1. Thermal strain of different adhesives

The thermal strain $\epsilon_{t h}$ is defined as: 


$$
\epsilon_{t h}=\frac{\Delta l(T)}{l_{0}}
$$

The coefficient of thermal expansion $\alpha$ is defined as:

$$
\alpha(T)=\frac{d \epsilon_{t h}}{d T}
$$

The resulting temperature dependent CTE is modeled with the following equation [3]:

$$
\alpha(T)=k_{1}+\frac{1}{2} k_{2}\left(1+\tanh \left[C\left(T-T_{g}\right)\right]\right)
$$

Note that the $\tanh \left[C\left(T-T_{g}\right)\right]$ part changes from -1 below $T_{g}$ to +1 above. Therefore, $\mathrm{k}_{1}$ and $\mathrm{k}_{1}+\mathrm{k}_{2}$ represent the linear coefficient of thermal expansion in the glassy and rubbery state respectively. The coefficient $\mathrm{C}$ determines the smoothness of the slope change. The thus modeled CTE of the different sets of adhesives are presented in figure 2 . The ratio of CTE between glassy and rubbery region is about 3 for epoxies and 4-5 for silicon rubbers.

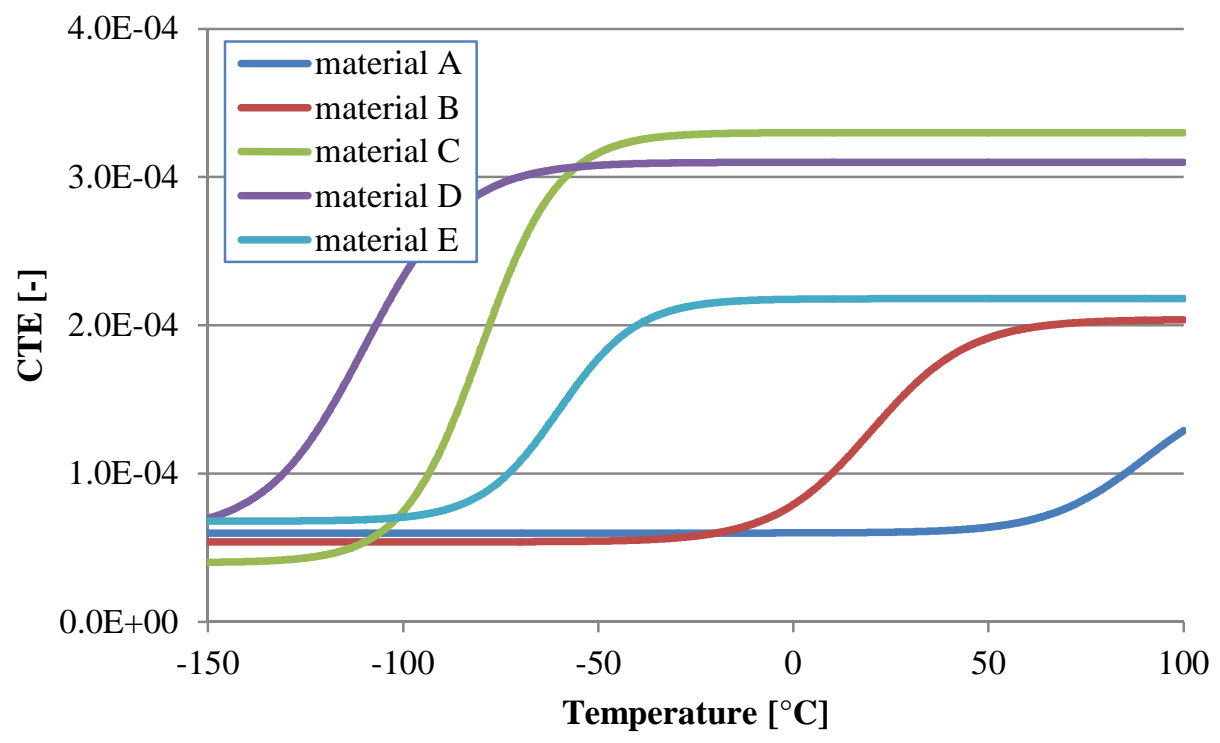

Figure 2. Temperature dependent coefficient of thermal expansion of different adhesives.

\section{VISCOELASIC SHEAR MODULUS}

The Young's modulus E of materials is usually measured with a uniaxial stress-strain test. In such a test the build-up of stress is measured as the specimen is elongated at a constant rate. Test are carried out with rectangular bars or dog-bone shaped specimens according to ASTM standards. However, since the mechanical behavior of viscoelastic materials depends on loading time and loading speed, stress-strain tests are not suited for determining viscoelastic properties. Commonly used methods to derive viscoelastic properties are: Creep experiments, relaxation experiments and dynamic 
experiments. The latter one is the most commonly used in characterizing viscoelastic materials. Also in this work dynamic mechanical experiments (DMA) are performed to determine the viscoelastic shear modulus.

A dynamic mechanical analyzer (Anton Paar MCR 301) is used for determining viscoelastic properties of adhesives. For determining the shear modulus, a sinusoidal torsional strain of $0.05 \%$ is applied at the following frequencies: [0.3, $1,3.2$ and $10 \mathrm{~Hz}$. The specimens are heated from $-150{ }^{\circ} \mathrm{C}-+100^{\circ} \mathrm{C}$ at a heating rate of $1{ }^{\circ} \mathrm{C} / \mathrm{min}$. The sample geometry is $[50 \mathrm{X} 5 \mathrm{X} 0.5 \mathrm{~mm}]$. Resulting shear storage modulus at $1 \mathrm{~Hz}$ is given in figure 3.

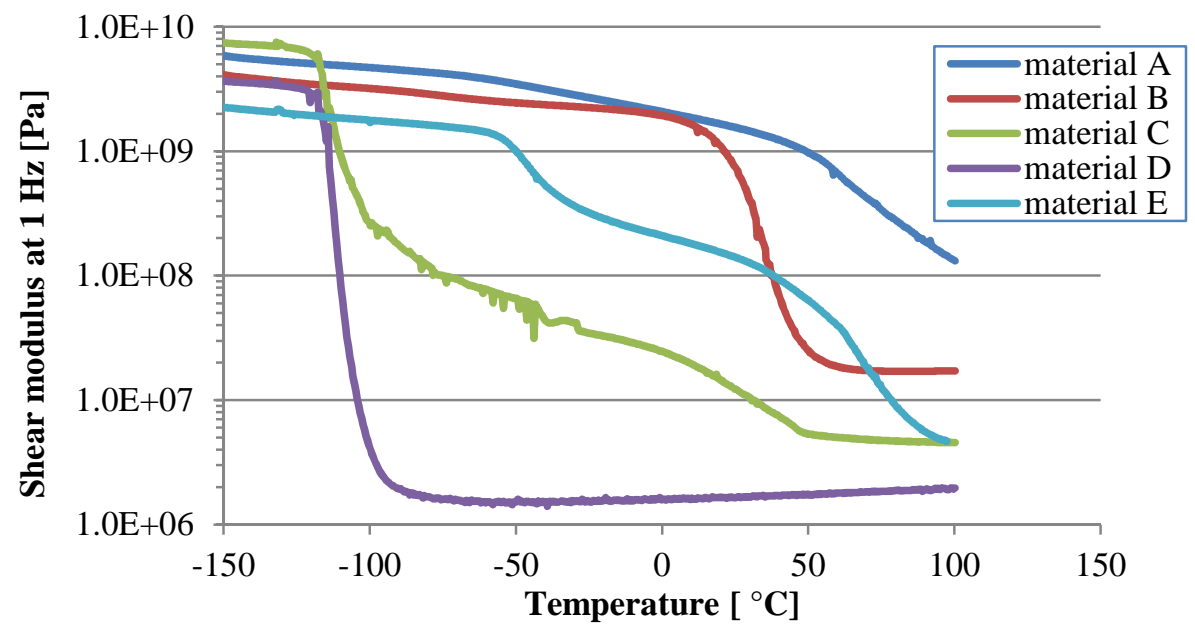

Figure 3. shear storage modulus as a function of temperature at $1 \mathrm{~Hz}$.

Form Figure 3 the glassy and rubbery shear modulus can be determined. The glass transition temperature is determined as that temperature at which the properties suddenly change. Table 1 gives an overview of these results.

The viscoelastic Young's modulus is determined similarly by performing sinusoidal tensile experiments at the same frequencies.

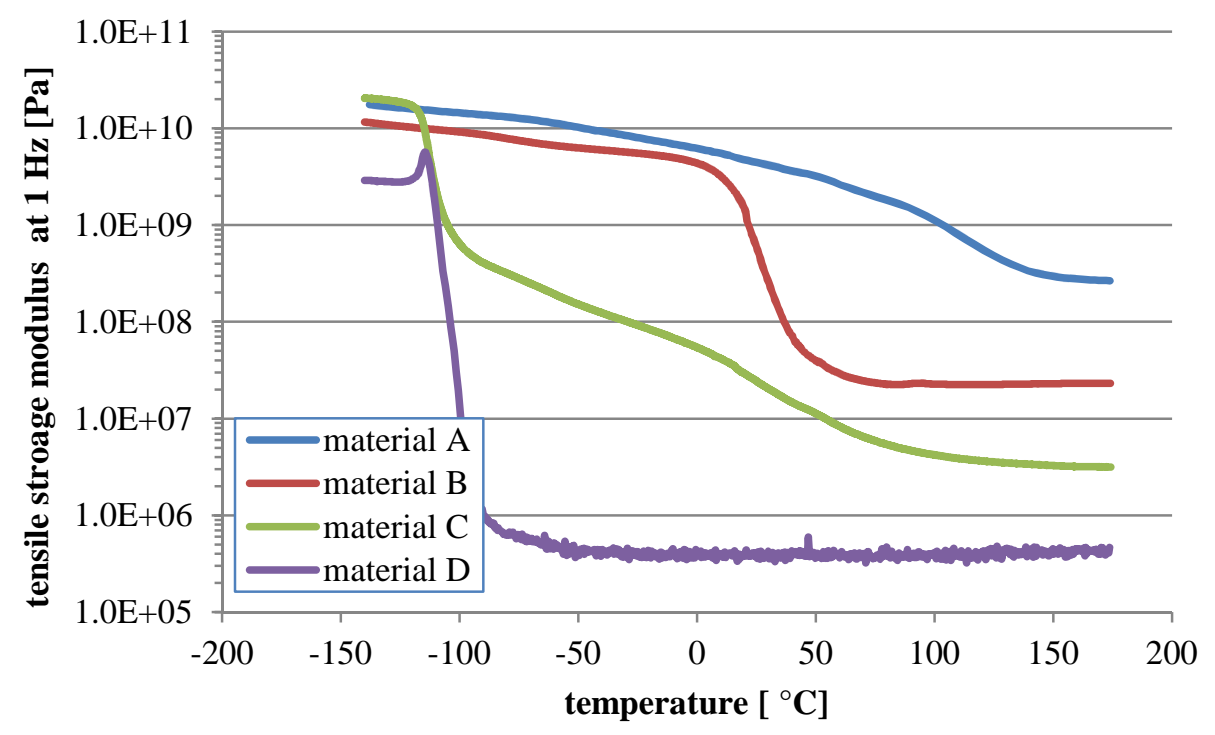

Figure 4. tensile storage modulus as a function of temperature at $1 \mathrm{~Hz}$. 
Table 1. Derived properties from DMA experiments.

\begin{tabular}{|l|l|l|l|l|l|l|}
\hline Material: & $\begin{array}{l}\text { Glassy shear } \\
\text { modulus [GPa] }\end{array}$ & $\begin{array}{l}\text { Rubbery shear } \\
\text { modulus [MPa] }\end{array}$ & $\begin{array}{l}\text { Glassy tensile } \\
\text { modulus [GPa] }\end{array}$ & $\begin{array}{l}\text { Rubbery tensile } \\
\text { modulus [MPa] }\end{array}$ & $\mathrm{T}_{\mathrm{g}}\left[{ }^{\circ} \mathrm{C}\right](\mathrm{DMA})$ & $\mathrm{T}_{\mathrm{g}}\left[{ }^{\circ} \mathrm{C}\right](\mathrm{CTE})$ \\
\hline Material A & 7.3 & -- & 17.5 & 275 & +80 & +90 \\
\hline Material B & 4.2 & 17.0 & 11.6 & 22.8 & +25 & +20 \\
\hline Material C & 7.4 & $<4.0$ & 20.3 & 3.2 & $-110,25$ & -80 \\
\hline Material D & 2.2 & 1.8 & -- & 0.4 & -110 & -110 \\
\hline Material E & 4.8 & $<2.0$ & -- & -- & $-50,+75$ & -60 \\
\hline
\end{tabular}

A large difference of typical 2-3 orders of magnitude between glassy and rubbery elastic behavior is found for all adhesives. Material $\mathrm{C}$ and $\mathrm{E}$ show 2 transition regions. These materials are compounds of epoxy and rubber material which causes multiple transition regions.

Within the context of small strain theory, the constitutive equation for an isotropic viscoelastic material can be written as:

$$
\sigma(t)=\int_{0}^{t} 2 G(t-\tau) \frac{d e}{d \tau} d \tau+I \int_{0}^{t} K(t-\tau) \frac{d \Delta}{d \tau} d \tau
$$

Where, $\sigma$ is the Cauchy stress, e is the deviatoric part of the strain, $\Delta$ is the volumetric part of the strain, $G(t)$ is the shear relaxation kernel, $K(t)$ is the bulk relaxation kernel, $\mathrm{t}$ is current time, $\tau$ is past time, $\mathrm{I}$ is the unit tensor [4]. ANSYS uses the following kernel functions:

$$
\begin{aligned}
& G(t)=G_{0}\left[\alpha_{\infty}^{G}+\sum_{i=1}^{n_{G}} \alpha_{i}^{G} \exp \left(-\frac{t}{\tau_{i}^{G}}\right)\right] \\
& K(t)=K_{0}\left[\alpha_{\infty}^{K}+\sum_{i=1}^{n_{K}} \alpha_{i}^{K} \exp \left(-\frac{t}{\tau_{i}^{K}}\right)\right]
\end{aligned}
$$

Where, $\mathrm{G}_{0}$ is the glassy shear modulus, $\mathrm{K}_{0}$ is the glassy rubbery modulus, $\tau_{i}$ are relaxation times, $G_{0} \cdot \alpha_{\infty}^{G}$ is the rubbery modulus, while $\alpha_{\infty}^{G}+\sum_{i=1}^{n_{G}} \alpha_{i}^{G}=1$.

A viscoelastic material model should therefore contain the parameters $G_{0}, K_{0}, \tau_{i}, \alpha_{\infty}$ and $\alpha_{i}$. The $\tau_{i}$ and $\alpha_{i}$ terms are the so called Prony terms. Normally, 15 Prony terms are sufficient for accurate fitting of material data.

The viscous properties of materials depend strongly on temperature. Thermorheological simplicity is an assumption based on the observation for many glass-like materials, like adhesives, of which the relaxation curve at high temperatures is identical to that at a low temperature if the time is properly scaled. In essence it assumes that the relaxation times (of all Prony coefficients) obey the following scaling law: 


$$
\tau_{i}=\frac{\tau_{i}\left(T_{R}\right)}{A\left(T, T_{R}\right)}
$$

Here, $A\left(T, T_{R}\right)$ is called the shift function. Many definitions exist. In this work the WLF shift function is used.

$$
\log _{10}(A)=\frac{\lambda_{2}\left(T-\lambda_{1}\right)}{\lambda_{3}+T-\lambda_{1}}
$$

Where, $\mathrm{T}$ is the current temperature, $\lambda_{1}$ is a reference temperature which is often chosen to be the glass transition temperature, $\lambda_{2}$ and $\lambda_{3}$ are fitting parameters.

The shear kernel $G(t)$ of material B is given in figure 4, the WLF model of material B is given in figure 5.

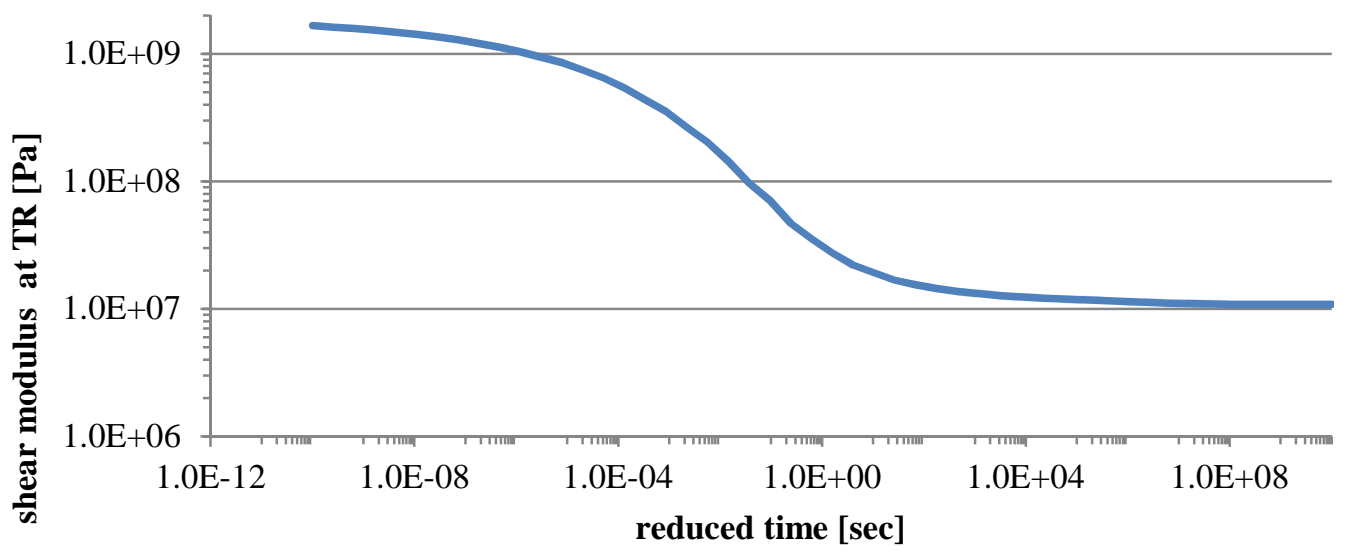

Figure 5. Kernel function $G(t)$ of material B

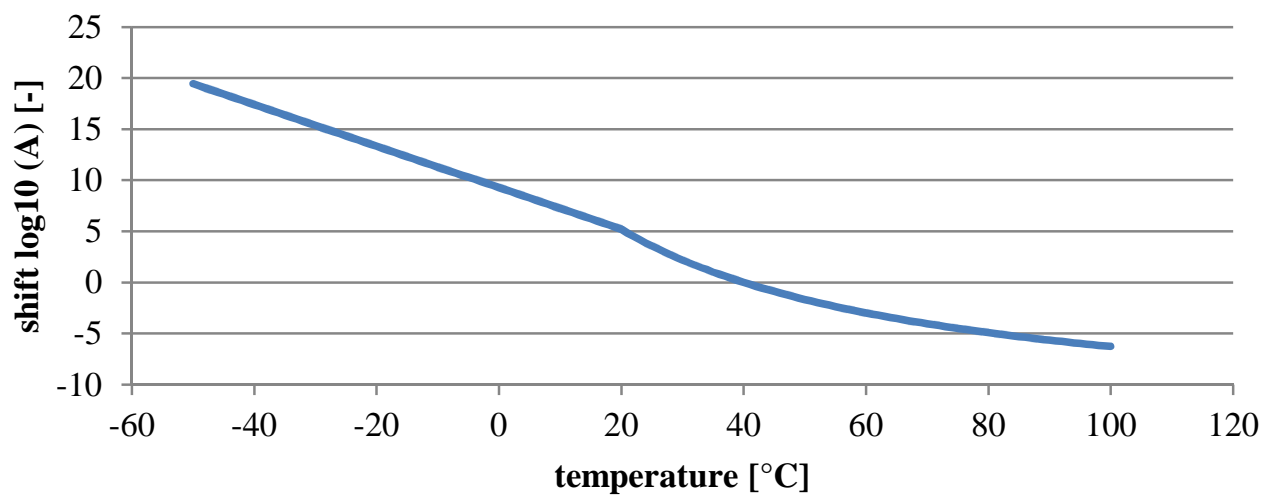

Figure 6. Shift function of material B

For details about modeling of experimental results and implementation in finite element code is referred to $[2,4,7]$. 


\section{BULK MODULUS}

The bulk modulus $\mathrm{K}$ is defined as the resistance to hydrostatic compression. In the case of viscoelastic materials, the bulk modulus depends on temperature. In various research projects it is shown that creep or relaxation behavior in purely hydrostatic compressed loading cases is of minor influence. Therefore, in this work we assume that the bulk modulus is independent of loading history [5].

The temperature bulk modulus is not directly measured but is obtained from shear and tensile experiments (See figure 3 and 4):

$$
K(T) \approx \frac{G(T) E(T)}{9 G(T)-3 E(T)}
$$

\begin{tabular}{|l|l|l|}
\hline Material: & $\begin{array}{l}\text { Glassy bulk } \\
\text { modulus [GPa] }\end{array}$ & $\begin{array}{l}\text { Rubbery bulk } \\
\text { modulus [MPa] }\end{array}$ \\
\hline Material A & 9.7 & -- \\
\hline Material B & 17.7 & 10.4 \\
\hline Material C & 24.3 & -- \\
\hline Material D & -- & 5.9 \\
\hline
\end{tabular}

Since the shear experiment is not carried completely in the rubbery region of material A the rubbery bulk modulus could not be determined for this material. The tensile experiment with material D failed in the glassy regime, hence the glassy bulk modulus is not determined.

The bulk compliance $\beta$ is modeled with the Tait equation [3,7]:

$$
\beta=k_{1} s_{0}+\frac{1}{2} k_{2} s_{0}\left[1+\tanh \left(C\left(T-T_{g}\right)\right)\right]+\frac{c_{1}}{B(T)}
$$

Where:

$B(T)=b_{1} \exp \left(-b_{2} \cdot T\right)$

The coefficients $k_{1}, k_{2}, C, T_{g}$ are the same coefficients used in the CTE model as shown in equation 3. The parameters, $s_{0}, c_{1}, b_{1}, b_{2}$ are fitting parameters. The bulk modulus $K$ is equal to:

$$
K \approx \frac{1}{\beta}
$$

The above described model is an elastic temperature dependent model. Therefore it is not needed to define the Prony terms $\tau_{i}^{K}$ and $\alpha_{i}^{K}$. If one does, all $\alpha_{i}^{K}$ terms should be zero. The temperature dependent $\alpha_{\infty}^{K}$ term is implemented in ANSYS by defining a table.

\section{VALIDATION EXPERIMENTS}

For validation purposes, aluminum plates were molded with adhesive material A, B, C, D and E. In this way double layered panels are created. Due to CTE mismatch the panels will warp as a result of a thermal loading. The dimensions of the double layered panels are as follows: Width X Length: $60 \mathrm{X} 60 \mathrm{~mm}$, thickness aluminum is $0.2 \mathrm{~mm}$, thickness of the adhesive layer is $0.5 \mathrm{~mm}$. The panels are exposed to a thermal loading, while the warpage of the panel is directly 
being detected. A Topography Deformation Measurement (TDM) device of INSIDIX is used to detect the topography of the panels. With the same device, the temperature of the panels is programmed as shown in figure 7.

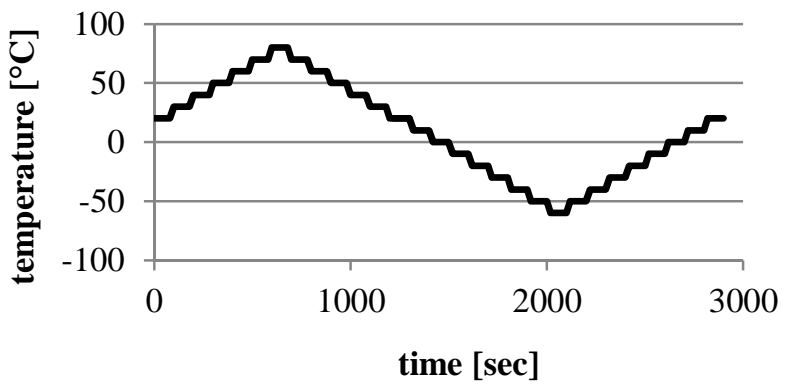

Figure 7. Applied temperature profile to the double layered panels.

The TDM, presented in figure 8 measures in a non-intrusive way the surface shape of samples of interest. By projecting fringe patterns on the surface of a sample and recording shadow patterns, the topography of the sample surface can be calculated. Heating/cooling elements in combination with a thermocouple connected to the double layered panel are used to control the temperature. The warpage is measured at elevated temperatures during a thermal ramp see figure 9 and 10.
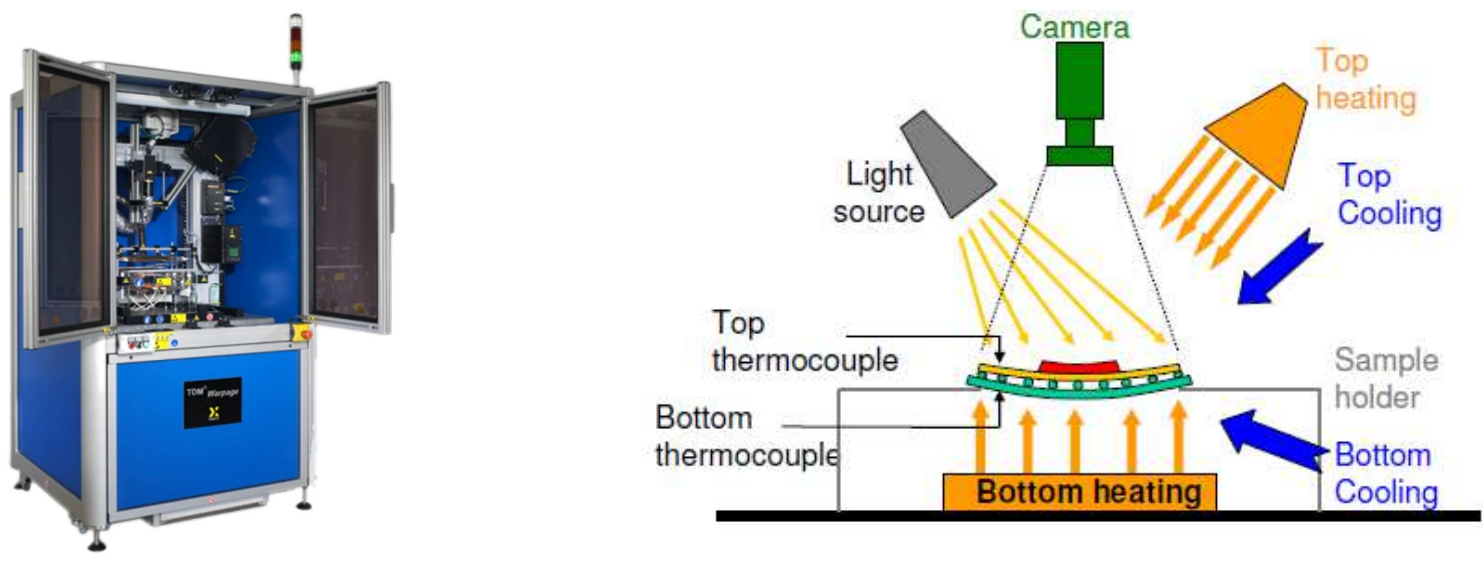

Figure 8. Topography and Deformation Measurement device of INSIDIX

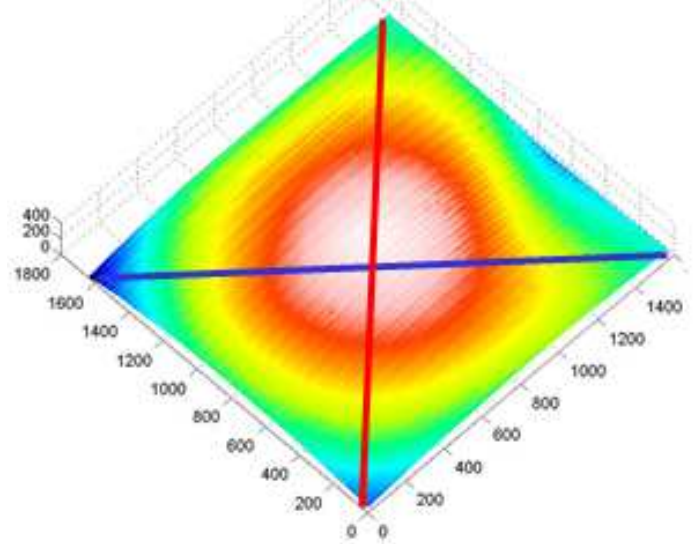

Figure 9. topography of a double layered panel at Figure 10. Out of plane deformation of a panel at $10{ }^{\circ} \mathrm{C}$ room temperature

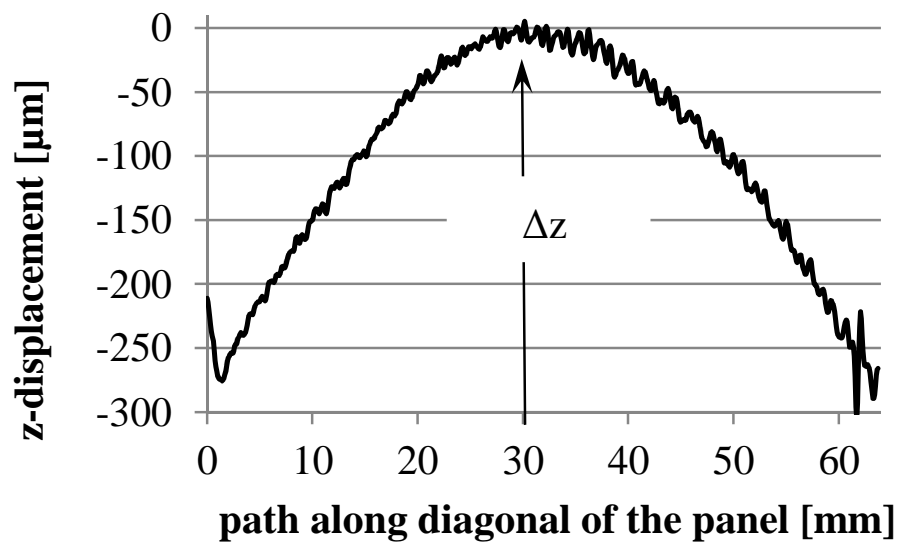


The thermo-mechanical deformation of an aluminum panel covered with adhesive B is given in figure 11 . The deformation is compared with finite element calculations. The double layered panel is modeled with 20 node elements. A transient thermal loading is applied as shown in figure 7.

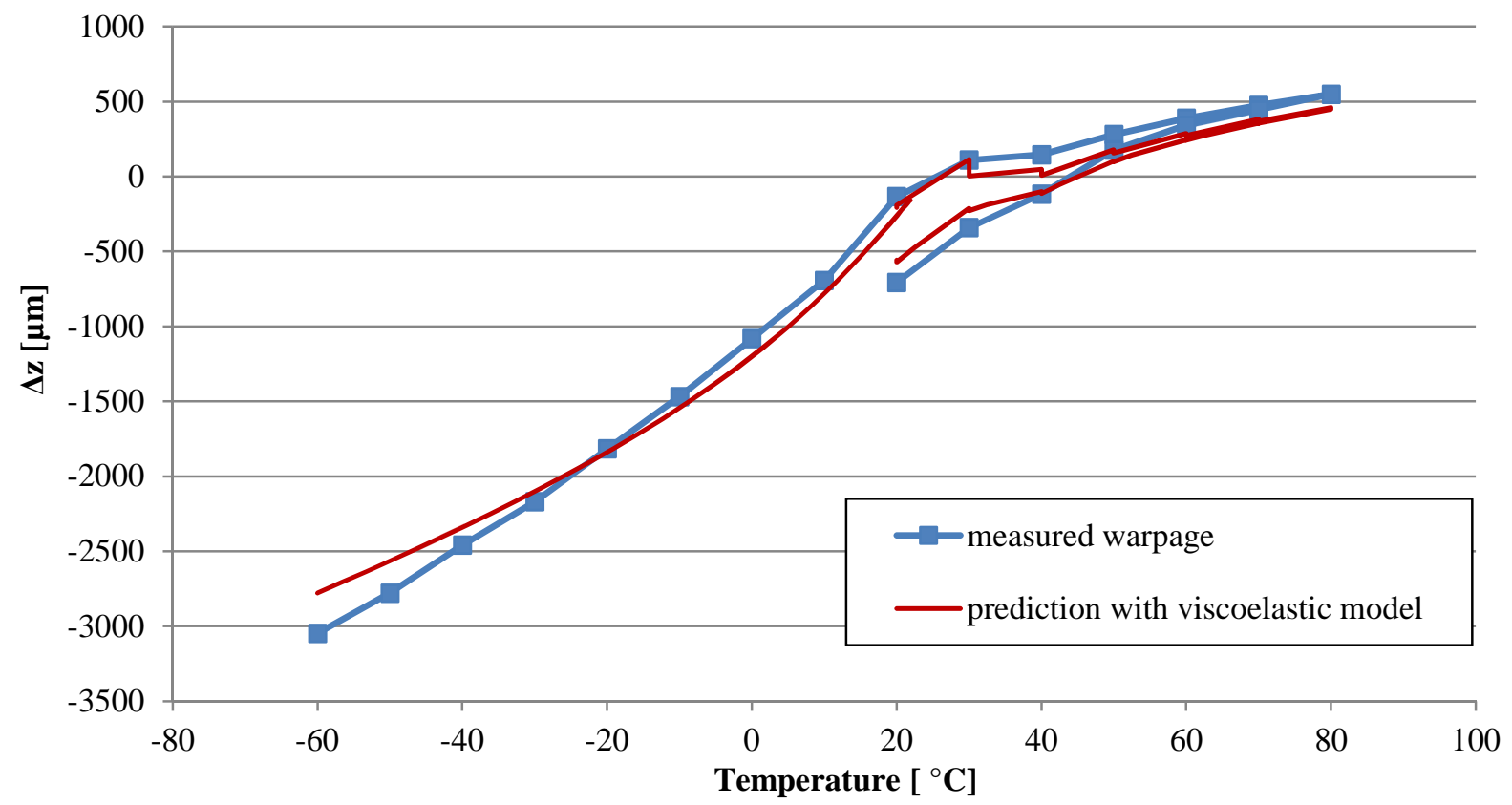

Figure 11. Warpage $\Delta \mathrm{z}$ as a function of temperature. The blue dotted line represents the measured warpage, the straight red line represents calculated warpage obtained with the viscoelastic material model.

As shown in figure 11, warpage predictions obtained with the viscoelastic model agree well with the measured warpage for the full range of temperature. An elastic material model results in warpage overprediction at temperatures above 20 ${ }^{\circ} \mathrm{C}$. At temperatures below $20^{\circ} \mathrm{C}$ the elastic model is suitable for stress and deformation calculations since this adhesive shows negligible creep or relaxation behavior below $20^{\circ} \mathrm{C}$.

Small creep effects are found around the glass transition temperature. These small creep effects are also determined from finite element simulations. Since the heating rate was rather high in the experiment, the creep effects are small in this example.

\section{CONCLUSIONS AND FUTURE ACTIVITIES}

In this paper, a characterization method is shown for determining relevant mechanical properties of adhesives. The coefficient of thermal expansion, viscoelastic Young's and shear modulus are presented for 5 different sets of adhesives. A modeling method, suitable for implementation in finite element software is discussed. These models are capable to reliably predict stress relaxation and creep effects in bonded joints as a result from thermal loading history.

Future activities include incorporation of elastic-plastic behavior in the FE-models to facilitate failure prediction in bonded joints. 


\section{REFERENCES}

[1] Côté, P. and Desnoyers, N., "Thermal stress failure criteria for a structural epoxy" Proc. SPIE 8125, pp. 81250K81250K-12 (2011)

[2] Ward, I.M. and Sweeney, J. [The mechanical properties of solid polymers], John Wiley \& Sons, West Sussex, 2004

[3] Saraswat, M.K., Jansen, K.M.B. et al, "A characterization method for viscoelastic bulk modulus of molding compounds," Proc. $9^{\text {th }}$ EUROSIME, pp. 1-4

[4] Zienkiewics, O.C. [The finite element method volume 2 solid mechanics], McGraw-Hill, 2004

[5] Snow, A.W. "Simple dilatometer for thermoset cure shrinkage and thermal expansion," Journal of applied polymer science, 52(3), pp. 401-411

[6] Zoller. P., et al, "Apparatus for measuring pressure-volume, temperature relationships of polymers to 350 degrees C," Review of scientific instruments, 47(8), pp.948-952.

[7] De Vreugd, J. "The effect of aging on molding compound properties," PhD-thesis, Delft, 2011 